\section{Chemical reduction of nitrate by zerovalent iron nanoparticles adsorbed radiation-grafted copolymer matrix}

\begin{abstract}
$\overline{\text { Abstract. This research specifically focused on the development of a novel methodology to reduce excess ni- }}$ trate in drinking water utilizing zerovalent iron nanoparticles (nZVI)-stabilized radiation-grafted copolymer matrix. nZVI was synthesized by borohydrate reduction of $\mathrm{FeCl}_{3}$ and stabilized on acrylic acid (AAc)-grafted non-woven polyethylene/polypropylene (NWPE/PP-g-AAc) copolymer matrix, which was grafted using gamma radiation. The use of $n Z V I$ for environmental applications is challenging because of the formation of an oxide layer rapidly in the presence of oxygen. Therefore, radiation-grafted NWPE/PP synthetic fabric was used as the functional carrier to anchor nZVI and enhance its spreading and stability. The chemical reduction of nitrate by nZVI-adsorbed NWPE/PP-g-AAc (nZVI-Ads-NWP) fabric was examined in batch experiments at different $\mathrm{pH}$ values. At low $\mathrm{pH}$ values, the protective layers on $\mathrm{nZVI}$ particles can be readily dissolved, exposing the pure iron particles for efficient chemical reduction of nitrate. After about $24 \mathrm{~h}$, at pH 3, almost $96 \%$ of nitrate was degraded, suggesting that this reduction process is an acid-driven, surface-mediated process. The nZVI-water interface has been characterized by the 1-pK Basic Stern Model (BSM). An Eley-Rideal like mechanism well described the nitrate reduction kinetics. In accordance with green technology, the newly synthesized nZVI-Ads-NWP has great potential for improving nitrate reduction processes required for the drinking water industry.
\end{abstract}

Keywords: 1-pK Basic Stern Model • acid-driven surface-mediated process • Eley-Rideal like mechanism • priority contaminant $\bullet$ zerovalent iron nanoparticles

S. Y. Ratnayake ${ }^{\bowtie}$, A. K. Ratnayake

Sri Lanka Atomic Energy Board,

No. 60/460, Orugodawatta, Wellampitiya 10600,

Sri Lanka,

Tel.: +94 77341 0388, Fax: +94 112533448 ,

E-mail: sanduni@aeb.gov.lk

D. Schild, J. Luetzenkirchen

Institute for Nuclear Waste Disposal (INE),

Karlsruhe Institute of Technology (KIT),

P. O. Box 3640, 76021 Karlsruhe, Germany

E. Maczka, E. Jartych, M. Kosmulski

Faculty of Electrical Engineering and Computer

Science,

Lublin University of Technology,

38a Nadbystrzycka Str., 20-618 Lublin, Poland

R. Weerasooriya

National Institute of Fundamental Studies,

Hantana Road, Kandy, 20000, Sri Lanka

Received: 21 April 2017

Accepted: 13 December 2017

\section{Introduction}

Nitrate contamination of global water resources because of globalization of modern agricultural practices is an emerging threat worldwide. In spite of the usefulness of nitrate and nitrogenous compounds as essential elements in the life process, nitrate is potentially hazardous when present in drinking water at sufficiently high concentrations. It acts as a precursor for several health hazards ranging from blue baby syndrome to gastric cancer. As it neither forms insoluble minerals that would be removable as precipitates nor significantly adsorbs under aquifer conditions, reduction is the only possible way to decrease the nitrate contamination from groundwater. Concern for potential health consequences has led to the adoption of stringent nitrate standards $[1,2]$ (US EPA: $44 \mathrm{mg} / \mathrm{L}$ nitrate, WHO: $50 \mathrm{mg} / \mathrm{L}$ nitrate) in water for human consumption. Nitrate because of its high solubility is possibly the most widespread water contaminant $[3,4]$. As it is thermally stable, boiling has no effect on it. Although nitrate in itself is relatively non-toxic, it can be reduced bacterially to nitrite in the intestines of newborn infants and may result in the disease methemoglobinemia (i.e. blue baby syndrome). Therefore, it is considered 
that nitrates in drinking water should be treated as a serious health hazard.

Remediation of nitrate in water has been achieved by using biological or chemical techniques that remove nitrate by its destruction [5, 6]. However, there are many limitations associated with these two techniques. Denitrifying bacteria that are used most of the time in biological denitrification to convert nitrate to nitrogen gas may cause a serious risk of bacteriological contamination of drinking water. Additionally, this method shows slow reaction rates, pH sensitivity and poisoning of microbes by elevated nitrate levels, which limits its applicability in nitrate remediation. Chemical techniques such as selective ion exchange [5], catalytic denitrification [6], adsorption [7], reverse osmosis [8], distillation and electrodialysis $[5,8]$ transfer nitrate into another compartment without really destroying it. However, generation of massive wastes that have to be treated separately to ensure a healthy environment [9] is a serious issue related to these techniques. Although several alternatives such as photo-assisted denitrification [10] or membrane bioreactors [11] were recently suggested to minimize the generation of wastes, the practical implementations of these techniques are still at the experimental stage. Moreover, several chemical denitrification processes have also been suggested to decontaminate nitrate-rich waters. The crucial step is to facilitate transfer of five electrons to convert nitrate to nitrogen gas. Substances such as nZVI can play a major role in this situation because it is a potent electron-donating source. Owing to some valuable properties such as high specific surface area, highly active surface and easily being scattered effect lead to the effective denitrification. Even though the catalytic role of $\mathrm{nZVI}$ in the destruction of organic pollutants has been studied for several decades [12], only a few investigations have been carried out on the applicability of nZVI in nitrate reduction [13-15]. However, most of them are limited to the laboratory scale and many issues are associated with the implementation. As an example, the stability of the active component (nZVI) may be a problem in the real-world application because the use of nZVI for environmental applications is challenging because of rapid formation of an oxide layer in the presence of oxygen. In our previous work, a procedure that would improve the applicability was developed [16]. The main objective of the previous work was to synthesize air-stable nZVI and enhance its stability by incorporating it into a radiation grafted NWPE/ PP polymer matrix. This stabilization was achieved by mixing of nZVI with the polyacrylic acid (PAA) grafted non-woven polyethylene/polypropylene, NWPE/PP (NWPE/PP-g-PAA) polymer matrix and allowing those nanoparticles to adhere on to the radiation-grafted copolymer matrix. This would also make it a more cost effective for the implementation at a large scale in developing countries such as Sri Lanka. Therefore, this research is specifically focused on a low-cost novel methodology to remove the nitrate from drinking water systems using an nZVI-stabilized, radiation-grafted copolymer matrix
(nZVI-Ads-NWP). The successful application of nZVI to the treatment of nitrate can be expected for the following reasons: (a) metallic Fe is a strong reducing agent for many redox-labile substances such as nitrate because of a standard reduction potential of $-440 \mathrm{mV}\left(\mathrm{Fe}^{2+}+2 \mathrm{e}^{-} \rightarrow \mathrm{Fe}\right)$ [17] formed by metallic $\mathrm{Fe}$ and dissolved aqueous $\mathrm{Fe}^{2+}$; (b) the redox chemistry of Fe provides the essential first step in the development of a catalyst capable of mediating multiple electron transfer in abiotic reactions, which bypass the activity of biological systems; (c) the recent developments made concerning metallic Fe in water treatment have created a need for more process-level insight into the chemistry of aqueous contaminant Fe systems in order to understand their performance in a better way; (d) metallic iron provides an inexpensive, readily available, and non-toxic starting material for the development of water treatment process.

The results obtained in this work suggest that metallic Fe can support the chemical reduction of nitrate contaminated water. The current literature includes different treatment methods based on ZVI. However, it was noted on several occasions that the kinetics of nitrate reduction by ZVI under controlled experimental conditions for oxygen, temperature and so on is strongly dependent on the $\mathrm{pH}$. In most of the previous work, the mechanistic aspects of nitrate reduction by ZVI have no common consensus. However, a wide variety of kinetic models for nitrate reduction by ZVI has been published ranging from first order with respect to $\left[\mathrm{NO}_{3}^{-}\right]$to those with apparent higher or lower order. Similarly, shifting order models can be constructed corresponding to mechanisms similar to the Langmuir-Hinshelwood or Eley-Rideal approach.

\section{Materials and method}

\section{Materials}

The nZVI-Ads-NWP was used as the iron source. The preparation and extensive characterization of the material has been previously reported [16]. For the present work, all chemicals used were of analytical grade. The glassware was cleaned first by soaking in diluted $\mathrm{HCl}$ solution followed by thorough washing with distilled water obtained from Milli-Q purification system.

\section{Method}

The nitrate reduction kinetics was examined by nZVI-Ads-NWP as a function of $\mathrm{pH}$. Particular attention was paid to optimize the reduction pathway to produce ammonia gas or ammonium ion. In order to understand the role of nZVI in the nitrate reduction, the energetic of the possible steps of nitrate decomposition on the surface of nZVI-Ads-NWP was calculated. The catalytic properties of the nanoclusters on the surface of the grafted fabric were indeed differing significantly from the other nZVI synthesis methods. The good catalytic activity 
is expected to relate to special sites, such as atom size steps, on the cluster. By carefully examining the reactivity of different sites of nZVI on the radiation-grafted surface, feasible pathways for ammonium/ ammonia production were identified. Once the feasible pathway was identified, several experiments were carried out along the direction of the calculations. The effects of $\mathrm{pH}$ on nitrate reduction by nZVI-Ads-NWP were examined under buffered and unbuffered conditions. The chemical measurements include the detection of nitrate, nitrite, ammonia, $\mathrm{pH}$ and iron species. In all cases, a mass balance with respect to nitrogen was calculated from the chemical data. The measurements concerning nitrogen species were carried out by ion chromatography. The $\mathrm{NO}_{x}$ products were determined by thermal conductivity detector-gas chromatography (TCD-GC). The effect of the initial $\mathrm{pH}$ on the reduction of nitrate was investigated by applying $1.2 \mathrm{~g} / \mathrm{L}$ of nZVI-Ads-NWP to a nitrate solution with $0.723 \mathrm{mM}$ concentration within $24 \mathrm{~h}$. The same experiments were conducted using ZVI as a reductant to assess the efficiency of nZVI for nitrate reduction. Figures 2-4 show experimental results obtained for both the fabric and ZVI particles at $\mathrm{pH} 3.0,4.0$ and 5.0, respectively.

\section{Results and discussion}

\section{Characterization of data from previous study}

The material has been extensively characterized in the previous study [16]. Here, only those points that are relevant to the present study are briefly reviewed.

\section{Scanning electron microscopy (SEM) analyses}

The corresponding secondary electron (SE) SEM and backscattered electron (BSE) SEM images confirm that PAA was properly grafted onto the NWPE/PP fabric during irradiation and the $\mathrm{nZVI}$ are well dispersed and stabilized on the NWPE/PP-g-PAA fabric surface.
Fourier-transform infrared spectroscopy (FTIR) analyses

FTIR spectra in attenuated total reflectance (ATR) mode were compared for ungrafted, grafted and nZVI-adsorbed grafted surfaces as shown in Fig. 1. The features of the ungrafted spectrum are changed once the surface was grafted with AAc as seen in the spectrum of NWPE/PP-g-PAA. Incorporation of carboxylate groups is evident with the appearance of new peaks at 1710, 1240 and $1160 \mathrm{~cm}^{-1}$. Emerging of a broadband around $3300 \mathrm{~cm}^{-1}$ in the spectrum of nZVI adsorbed grafted fabric is due to the formation of hydrogen bonded $\mathrm{O}-\mathrm{H}$ on the surface upon adsorption of nZVI. This observation suggests that nZVI adsorbed onto the surface via one $\mathrm{O}$ atom of the O-C-O moiety with monodentate configuration while the other $\mathrm{O}$ atom, which is from the $\mathrm{C}=\mathrm{O}$ group, participates in $\mathrm{H}$-bonding [16]. Adsorption of nZVI to the polymer surface with the formation of a core-shell structure is evidenced by the appearance of new bands in the region $600-450 \mathrm{~cm}^{-1}$ due to $\mathrm{Fe}-\mathrm{O}$ vibrations. Invariant bands of the original polyethylene surface at $2910,2850,1480,1460$ and $630 \mathrm{~cm}^{-1}$ depict the radiation-grafted non-woven synthetic fabric that acts as a supporting material to anchor $\mathrm{nZVI}$ and enhances its spreading and stability.

\section{$X$-ray diffraction $(X R D), X$-ray photoelectron spectroscopy (XPS) and Mössbauer analyses}

It was confirmed that iron nanoparticles have a core of zerovalent iron $\left(\mathrm{Fe}^{0}\right)$ and a shell of mainly iron oxides $\left(\mathrm{Fe}_{2} \mathrm{O}_{3}\right)$.

\section{Proton titrations and zeta potential}

The nZVI-water interface has been fully characterized by the 1-pK BSM as described in detail elsewhere [16].

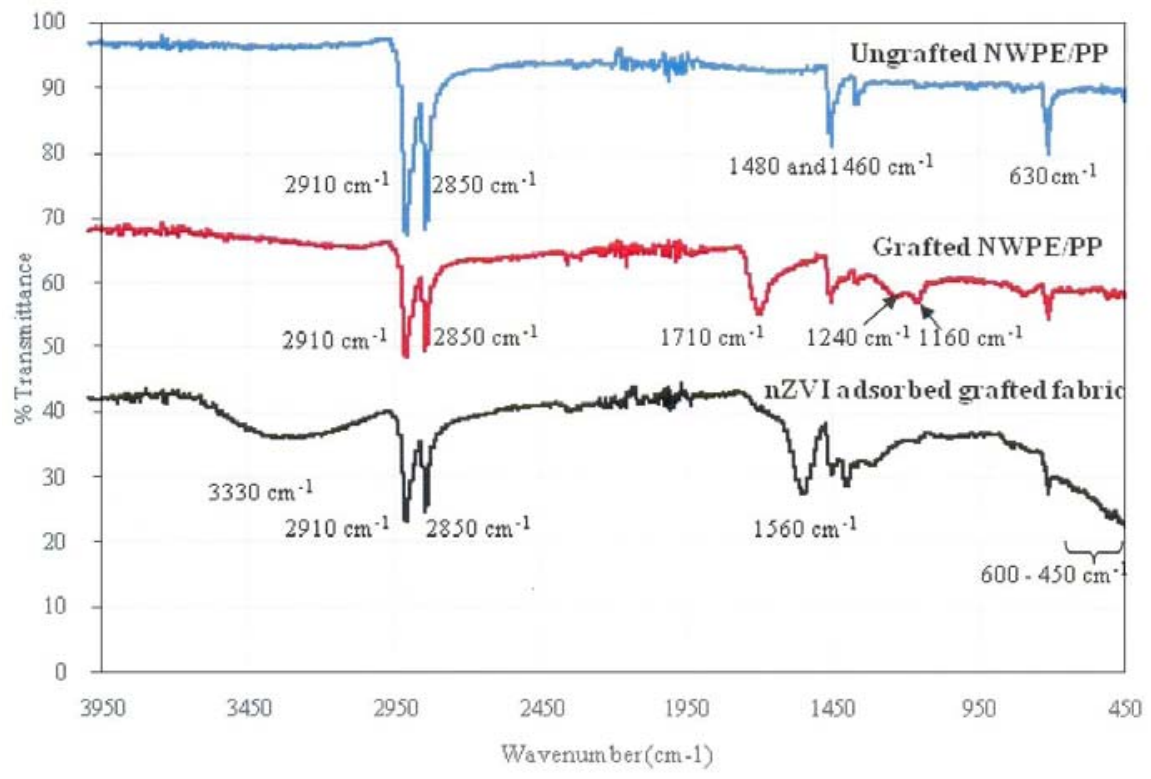

Fig. 1. ATR-FTIR spectra of ungrafted NWPE/PP, NWPE/PP-g-PAA and nZVI-Ads-NWP fabric. 
Table 1. Percentage reduction values of nitrate at different $\mathrm{pH}$ values

\begin{tabular}{lcc}
\hline Initial pH & $\begin{array}{c}\text { Fabric nZVI } \\
\text { sample }\end{array}$ & $\begin{array}{c}\text { ZVI } \\
\text { sample }\end{array}$ \\
\hline 3.0 & 96.07 & 78.29 \\
4.0 & 87.50 & 73.67 \\
5.0 & 79.55 & 39.49 \\
\hline
\end{tabular}

a

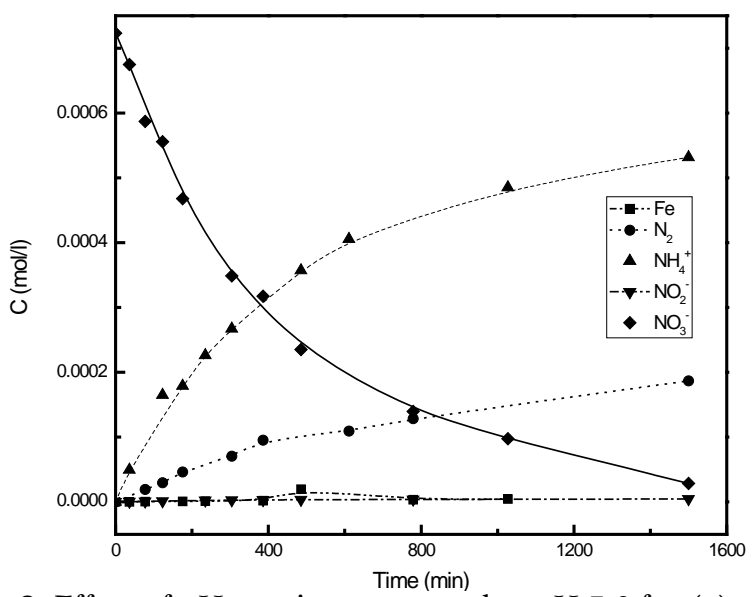

Effect of initial $\mathrm{pH}$ value on the reduction of nitrate

The data for percentage reduction of nitrate in Table 1 illustrate that the $\mathrm{pH}$ of the solution showed a marked effect on nitrate reduction with optimum efficiency around $\mathrm{pH} 3$.

After about $24 \mathrm{~h}$, at $\mathrm{pH} 3$, over $96 \%$ of nitrate was degraded using the nZVI-adsorbed fabric sample compared to that of about $78 \%$ for ZVI particles as

b

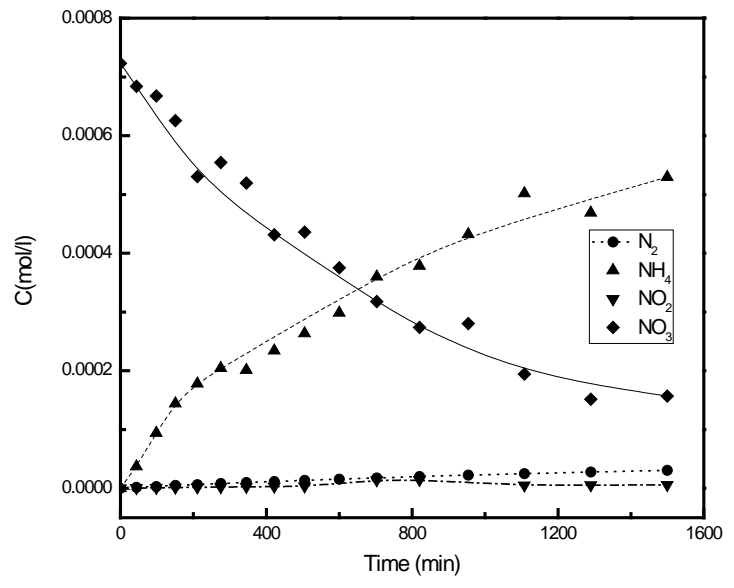

Fig. 2. Effect of pH on nitrate removal at pH 3.0 for (a) nZVI-Ads-NWP and (b) ZVI.

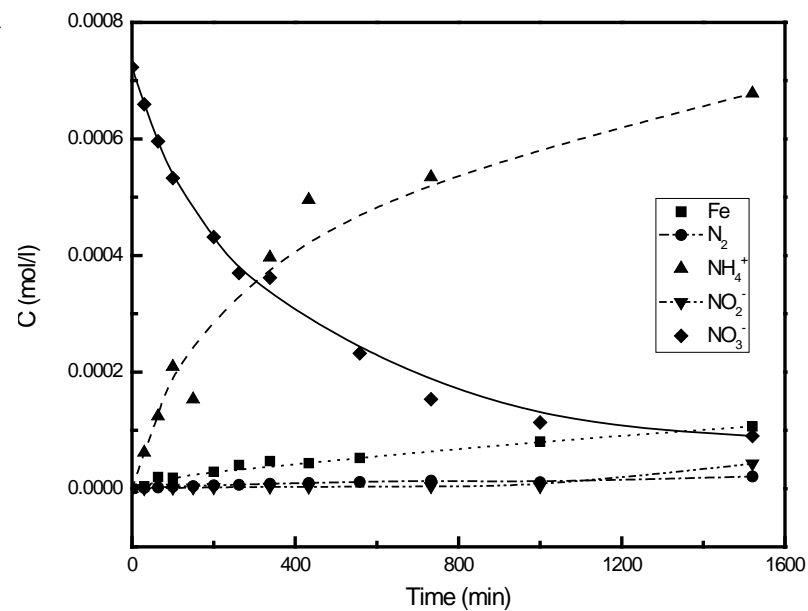

b

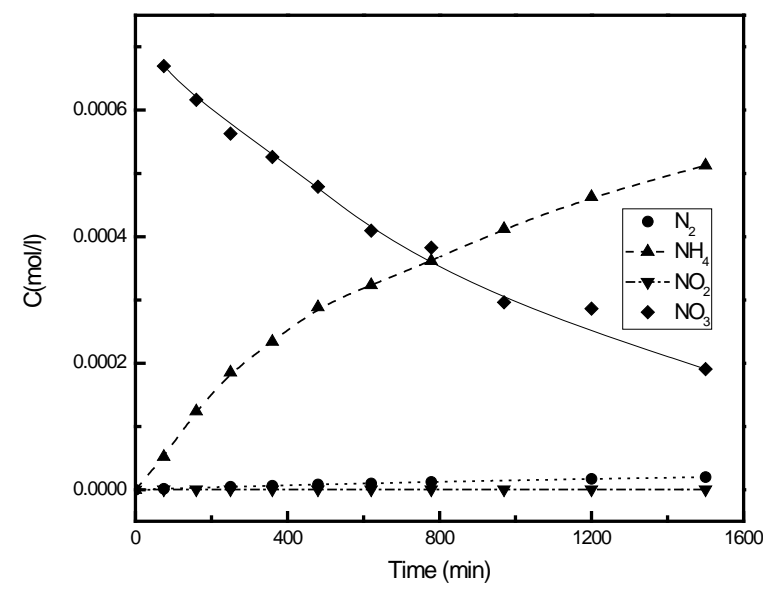

Fig. 3. Effect of $\mathrm{pH}$ on nitrate removal at $\mathrm{pH} 4.0$ for (a) nZVI-Ads-NWP and (b) ZVI.

a

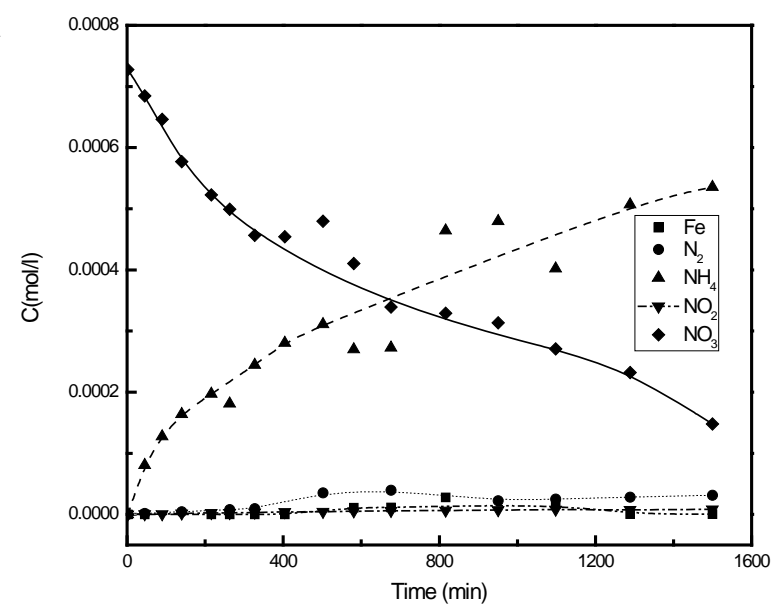

b

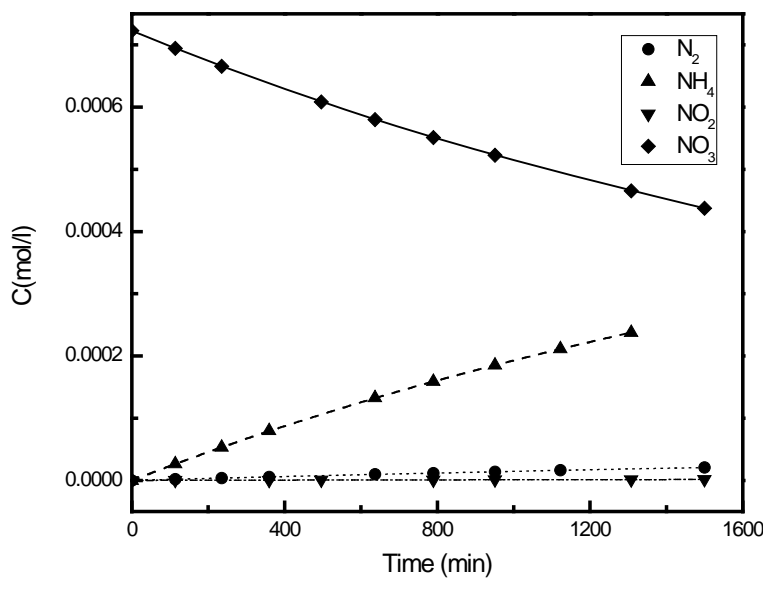

Fig. 4. Effect of pH on nitrate removal at pH 5.0 for (a) nZVI-Ads-NWP and (b) ZVI. 
depicted in Fig. 2. As mentioned earlier [18], there was no significant effect in the reduction of nitrate by ZVI for $\mathrm{pH}>4$. The nZVI-Ads-NWP showed more than $75 \%$ reduction of nitrate even around $\mathrm{pH}$ 5.0 as shown in Figs. 3 and 4. However, complete reduction of nitrate was never observed. Most of the previous studies achieved $100 \%$ removal of nitrate using freshly prepared ZVI particles that were used immediately after the synthesis because these particles are unstable in air $[18,19]$, which was limited by purging inert gas into the reaction medium and ZVI storage containers [20-23]. Only few studies $[24,25]$ were carried out using ZVI supported composites. In one of the studies, an nZVI-polystyrene anion exchange composite showed $80 \%$ reduction of nitrate at pH 6.0 [24]. In another study, nZVI supported in polystyrene-divinylbenzene copolymer showed $88.8 \%$ degradation of nitrate at $\mathrm{pH} 2.0$ and $100 \%$ degradation at $\mathrm{pH} 5.0$ [25].

The enhanced reduction of nitrate by ZVI or nZVI under more acidic conditions can be largely ascribed to the removal of the protective iron oxide layer, thus exposing metallic iron for the reaction. The protective layers on the surface of the nZVI yield the core-shell structure containing ferrous hydroxide and other protective layers. At low $\mathrm{pH}$ values, these protective layers can be readily dissolved exposing metallic iron for chemical reduction of nitrate.

\section{Evaluation of kinetic data and mechanism for nitrate reduction}

The development of a mechanistic model for nitrate reduction by nZVI is important particularly in applications related to environmental remediation. In analogue to reductive dehalogenation by metallic $\mathrm{Fe}$, the nitrate reduction process is believed to be a consequence of dissolution of $\mathrm{Fe}$ by water. As a result of the parallel reactions (dissolution of iron by water and nitrate reduction) with concomitant release of $\mathrm{Fe}^{2+}$ into solution and other related reactions, it appears that stoichiometry is of limited value in assessing reaction mechanisms. Hence, we have avoided this option.

In the previous study, the reactivity of nZVI has been characterized and the data showed the presence of a FeO layer encapsulating nZVI [16]. However, $\mathrm{NO}_{3}^{-}$retention by the $\mathrm{nZVI}$ (FeO encapsulated) is important and an essential step for its degradation. The 1-pK BSM should be considered foremost because of the uniqueness of the parameter estimation of proton titration data. Therefore, the nZVI $(\mathrm{FeO})$ and $\mathrm{H}_{2} \mathrm{O}$ interface has been fully characterized by a 1-pK BSM involving two surface site types $\equiv \mathrm{Fe}_{a} \mathrm{OH}^{-0.5}$ and $\equiv \mathrm{Fe}_{b} \mathrm{OH}^{-0.5}$. In the modelling of the charging behaviour of the nZVI, it was found that two distinct surface sites were necessary to model the data, that is, the use of one site was not sufficient to describe the experimental results. These generic sites (labelled $a$ and $b$ ) could correspond to oxygen sites of different co-ordination, for example, but it was noted that a structural assignment is not possible with the present knowledge. Before nitrate reduction by $\mathrm{nZVI}$, the anion has to be adsorbed to the nZVI surface. However, the nitrate adsorption density on nZVI cannot be accurately measured because of its low surface coverage. Nitrate ions are generally adsorbed weakly on solid surfaces. Therefore, conventional experimental methods cannot be used to quantify adsorption density. In this research, surface titrations were used to estimate weak adsorption capacity by a calculation according to the 1-pK BSM. The mass action coefficients used for these calculations are given in Table 2. Except $\mathrm{K}_{3}$ and $\mathrm{K}_{4}$, all other constants were obtained by modelling proton titrations in a given background electrolyte. In this method, high concentrations of nitrate, typically $0.01 \mathrm{M}$ were applied and rapid titrations were performed within $10 \mathrm{~min}$. Thus, nitrate reduction is limited.

As contact time increased, nitrate reduction by nZVI was clearly observed. The reduction process is believed to occur via the involvement of the surface species $\equiv \mathrm{Fe}_{a} \mathrm{OH}_{2}^{+0.5} \mathrm{NO}_{3}^{-}$and $\equiv \mathrm{Fe}_{b} \mathrm{OH}_{2}^{+0.5} \mathrm{NO}_{3}^{-}$yielding ammonia as a major product after reduction occurred. The presence of nitrite was also noted in the sample at minute concentrations.

In order to develop a mechanistic model to interpret nitrate reduction kinetics by nZVI, Eley-Rideal like mechanism was suggested according to the reactions shown as follows:

\section{Proton sorption:}

$$
\begin{array}{ll}
\mathrm{H}^{+}+\equiv \mathrm{Fe}_{a} \mathrm{OH}^{-0.5} \rightarrow \equiv \mathrm{Fe}_{a} \mathrm{OH}_{2}^{+0.5} & \mathrm{~K}_{1} \\
\mathrm{H}^{+}+\equiv \mathrm{Fe}_{b} \mathrm{OH}^{-0.5} \rightarrow \equiv \mathrm{Fe}_{b} \mathrm{OH}_{2}^{+0.5} & \mathrm{~K}_{2}
\end{array}
$$

Electrostatic sorption of $\mathrm{NO}_{3}^{-}$:

$$
\begin{aligned}
& \equiv \mathrm{Fe}_{a} \mathrm{OH}_{2}^{+0.5}+\mathrm{NO}_{3}^{-} \rightarrow \equiv \mathrm{Fe}_{a} \mathrm{OH}_{2}^{+0.5} \mathrm{NO}_{3}^{-} \mathrm{K}_{3} \\
& \equiv \mathrm{Fe}_{b} \mathrm{OH}_{2}^{+0.5}+\mathrm{NO}_{3}^{-} \rightarrow \equiv \mathrm{Fe}_{b} \mathrm{OH}_{2}^{+0.5} \mathrm{NO}_{3}^{-} \mathrm{K}_{4}
\end{aligned}
$$

The reactions (1)-(4) are assumed to attain pseudo equilibrium and the respective mass action coefficients are shown in Table 2. In order to model the kinetic data for nitrate, the Chemical Kinetic Simulation code was used. This code has the flexibility to incorporate reactions as specified above. It is important to note that the reaction orders shown in the table are not integers, which implies that the reactions defined in the proposed model require further refinements including additional mechanistic steps for better prediction of nitrate reduction by nZVI. However, the experimental data that would be required cannot be obtained by the kind of experiments performed so far. The proposed model provides a satisfactory phenomenological description of nitrate reduction on the materials under study. The identity of the surface sites is not known, and the non-integer coefficients in the rate laws also suggest that mechanistic understanding can only be gained by additional studies. Nevertheless, the coupling of the rate law with the surface complexation approach is promising in this respect. 


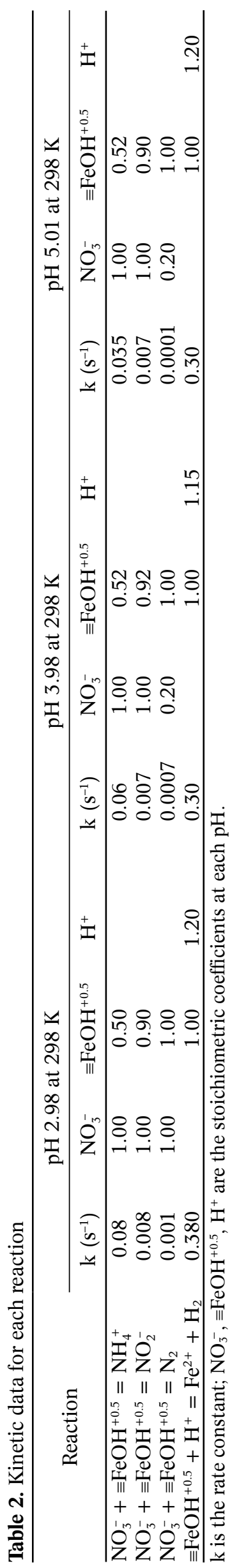

\section{Conclusion}

It can be concluded that the successfully synthesized stable nZVI on the radiation-grafted copolymer matrix can be applied for the treatment of nitrate-contaminated water. We obtained more than 96\% reduction of nitrate at $\mathrm{pH} 3.0$. As a consequence, this product may be effectively used for the reduction of nitrate in the purification process for drinking water. In particular, it could be a low-cost, efficient material for developing countries in this respect.

Acknowledgments. RW/SR thanked NRC 12-130 and Sri Lanka Atomic Energy Board for their financial support.

\section{References}

1. World Health Organization. (1974). Safe Drinking Water Quality Act Public Law 93-523. U.S. Government Printing Office.

2. World Health Organization. (2004). Guidelines for drinking-water quality. Vol. 1. Recommendations. Geneva: WHO.

3. Majumdar, D., \& Gupta, N. (2000). Nitrate pollution of groundwater and associated human health disorders. Indian J. Environ. Health, 42, 28-39.

4. Weerasooriya, S. V. R., \& Dissanayake, C. B. (1992) Modelling the nitrosation kinetics in simulated natural environmental conditions. Toxicol. Environ. Chem., 36, 131-137.

5. Guter, G. (1995). Nitrate removal from contaminated groundwater by anion exchange. In A. K. Sengupta (Ed.), Ion exchange technology: Advances in pollution control (pp. 61-113). Lancaster, PA: Technomic Publishing Co. Inc.

6. Mercado, A., Libhaber, M., \& Soares, M. I. M. (1988). In situ biological groundwater denitrification: Concepts and preliminary field tests. Water Sci. Technol., 20, 197-209.

7. Bhatnagar, A., \& Sillanpaa, M. (2011). A review of emerging adsorbents for nitrate removal from water. Chem. Eng. J., 168(2), 493-504.

8. Schoeman, J. J., \& Styen, A. (2003). Nitrate removal with reverse osmosis in a rural area in South Africa. Desalination, 155, 15-26.

9. Meile, L. J., \& Johnson, A. J. (1983). Waste generation reduction - nitrate FY State Report. Trends in analytical chemistry. USA.

10. Pintar, A., Bastista, J., \& Levec, J. (2001). Catalytic denitrification: Direct and indirect removal of nitrates from potable water. Catal. Today, 66(2/4), 503-510.

11. Urbain, V., Benoit, R., \& Manem, J. (1996). Membrane bioreactor: a new treatment tool. J. Am. Water Works Assoc., 88, 75-86.

12. Rhodes, F. H., \& Carty, J. T. (1925). The corrosion of certain metals by carbon tetrachloride. Ind. Eng. Chem., 17(9), 909-911.

13. Murfy, A. P. (1991). Chemical removal of nitrate from water. Nature, 350, 223-225.

14. Young, G. K., Bungay, H. R., Brown, L. M., \& Parson, W. A. (1964). Chemical reduction of nitrate in water. J. Water Pollut.Control Federation, 36, 395-398.

15. Siantar, D. P., \& Schreier, C. G. (1995). Transformation of the pesticide 1,2-dibromo-3-chloropropane (DBCP) and nitrate by iron powder and by $\mathrm{H}_{2} / \mathrm{Pd} /$ $\mathrm{Al}_{2} \mathrm{O}_{3}$. In American Chemical Society National Meet- 
ing, Washington, DC, April 2-6, 1995. American Chemical Society.

16. Ratnayake, S., Schild, D., Maczka, E., Jartych, E., Luetzenkirchen, J., Kosmulski, M., Makehelwala, M., Weragoda, S. K., Bandara, A., Wijayawardana, R., Chandrajith, R., Indrarathne, S. P., \& Weerasooriya, R. (2016). A novel radiation-induced grafting methodology to synthesize stable zerovalent iron naoparticles at ambient atmospheric conditions. Colloid Polym. Sci., 294(10), 1557-1569.

17. Atkins, P. W. (1986). Physical chemistry. Oxford University Press.

18. Yang, G. C. C., \& Lee, H. -L. (2005). Chemical reduction of nitrate by nano-sized iron: Kinetics and pathways. Water Res., 39, 884-894.

19. Wang, W., Jin, Z., Li, T., Zhang, H., \& Gao, S. (2006). Preparation of spherical iron nanoclusters in ethanolwater solution for nitrate removal. Chemosphere, 65, 1396-1404.

20. Hwang, Y. K. (2011). Mechanism study of nitrate reduction by nano zero valent iron. J. Hazard. Mater., 185, 1513-1521.
21. Choe, S., Chang, Y. -Y., Hwang, K. -Y., \& Khim, J. (2000). Kinetics of reductive denitrification by nanoscale zero-valent iron. Chemosphere, 41 , 1307-1311.

22. Rodriguez-Maroto, J. M., Garcia-Herruzo, F., GarciaRubio, A., Gomez-Lahoz, C., \& Vereda-Alonso, C. (2009). Kinetics of the chemical reduction of nitrate by zero-valent iron. Chemosphere, 74(6), 804-809.

23. Ahn, S. C., Oh, S. -Y., \& Cha, D. K. (2008). Enhanced reduction of nitrate by zero-valent iron at elevated temperatures. J. Hazard. Mater., 156(1/3), 17-22.

24. Jiang, Z., Zhang, S., Pan, B., Wang, W., Wang, X., Lv, L., Zhang, W., \& Zhang, Q. (2012). A fabrication strategy for nanosized zero valent iron (nZVI)polymeric anion exchanger composites with tunable structure for nitrate reduction. J. Hazard. Mater., 233/234, 1-6.

25. Jiang, Z., Lv, L., Zhang, W., Du, Q., Pan, B., Yang, L., \& Zhang, Q. (2011). Nitrate reduction using nanosized zero-valent iron supported by polystyrene resins: role of surface functional groups. Water Res., 45, 2191-2198. 